\title{
Visual interfaces for the digital simulation system of the IPR-R1 Triga nuclear research reactor
}

\author{
Amir Z. Mesquita ${ }^{1 *}$, Adriano de A. M. Felippe ${ }^{2}$, Aldo M. F. Lage ${ }^{1}$, and Patrícia A. M. Ribeiro ${ }^{1}$ \\ Centro De Desenvolvimento da Tecnologia Nuclear (CDTN), Campus da UFMG/Pampulha, CEP: 31970-901. Belo \\ Horizonte, MG, Brasil ${ }^{1}$ \\ Universidade Federal De Minas Gerais (UFMG), Campus da UFMG/Pampulha, CEP: 31970-901. Belo Horizonte, \\ MG, Brasil ${ }^{2}$ \\ Received: 19-August-2020; Revised: 25-October-2020; Accepted: 07-November-2020 \\ (C)2020 Amir Z. Mesquita et al. This is an open access article distributed under the Creative Commons Attribution (CC BY) \\ License, which permits unrestricted use, distribution, and reproduction in any medium, provided the original work is properly \\ cited.
}

\begin{abstract}
Nuclear Technology Development Center (CDTN) offers the Training Course for Research Reactor Operator (Ctorp). This course is offered since 1974 and about 250 nuclear professionals were certificated by CDTN. Thus, a digital simulation system for the IPR-R1 Triga research reactor was developed to be a tool for teaching, training and recycling professionals. The simulator was developed using the LabVIEW® (Laboratory Virtual Instruments Engineering Workbench), with support calculation software, where mathematical models and graphical interface configurations form a friendly platform, which allows the trainee to be identified with the physical systems of the research reactor. A simplified modeling of the main physical phenomena related to the operation of the reactor and the reactivity control systems, reactor cooling and reactor protection was used. The digital simulator allows an HMI (Human-Machine Interaction) by manipulating system variables and monitoring trends in quantities during the operation of the reactor, showing an interactive tool for teaching, training and recycling for professionals in the IPR-R1 Triga nuclear research, allowing simulations of the start, power and stop operations. This paper presents the design and results of the user visual interfaces developed for the reactor operation simulator. This is the equivalent part of structured text programming and, therefore, the most significant part of the developed simulator.
\end{abstract}

\section{Keywords}

Simulation, Modelling, Triga nuclear reactor, Virtual instruments, Visual interface, LabVIEW®.

\section{Introduction}

The IPR-R1 Triga research reactor (Radioactive Research Institute - Reactor 1, Training Research Isotope production, General Atomic) is located at the Nuclear Technology Development Center - CDTN (Belo Horizonte/Brazil). The IPR-R1 is used various purposes, such as research on neutronic and thermohydraulic, radioisotopes production, neutron radiography, neutron activation analysis, and for training and education. In Figure 1 is shown the IPR$\mathrm{R} 1$ Triga reactor core [1].

The IPR-R1 Triga reactor, like all reactors of this type, its core is cooled by natural circulation of demineralized water. The coolant passage through the upper plate is carried out through the space at the fuel element top and the hole in this plate.

*Author for correspondence

80
In the pool, water is pumped to a heat exchanger, where the heat is transferred to the secondary circuit. An external tower cools the water in the secondary circuit. In Figure 2 the circuit shows the complete coolant circuit. The diagram also shows the instrumentation distribution and the directions of forced and natural circulation in the IPR-R1 reactor pool.

The use of computer simulators has become more common in different areas of human activity. They are more necessary the greater the complexity of systems and their interactions with operators. The level of security required, depending on the possible consequences of a wrong operation, is a key factor for using training and retraining policies of the operators of those systems. Clear examples are the necessary policies for training and retraining aircraft pilots, ships, automobiles, complex industrial plants and, mainly, nuclear reactors. 


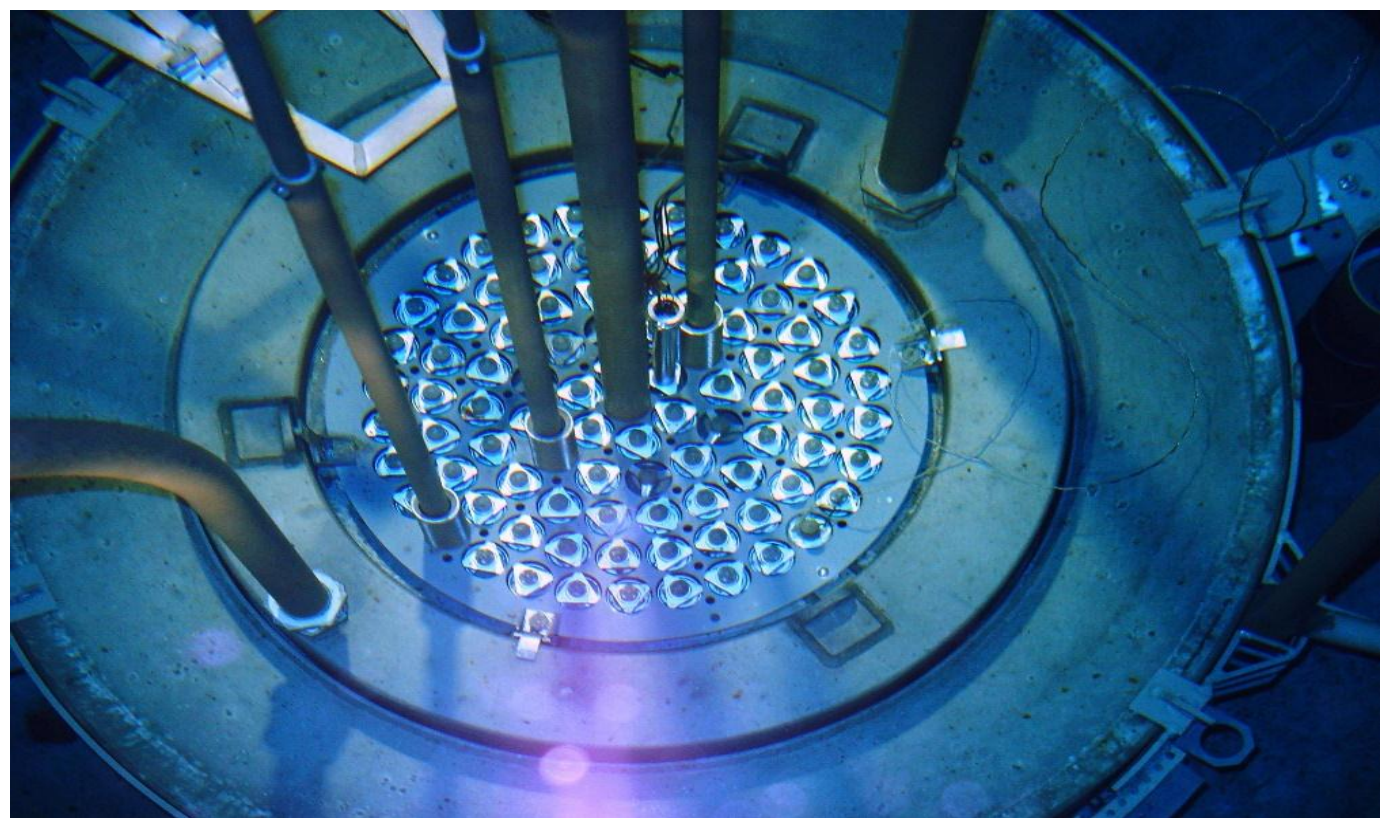

Figure 1 IPR-R1 Triga reactor core

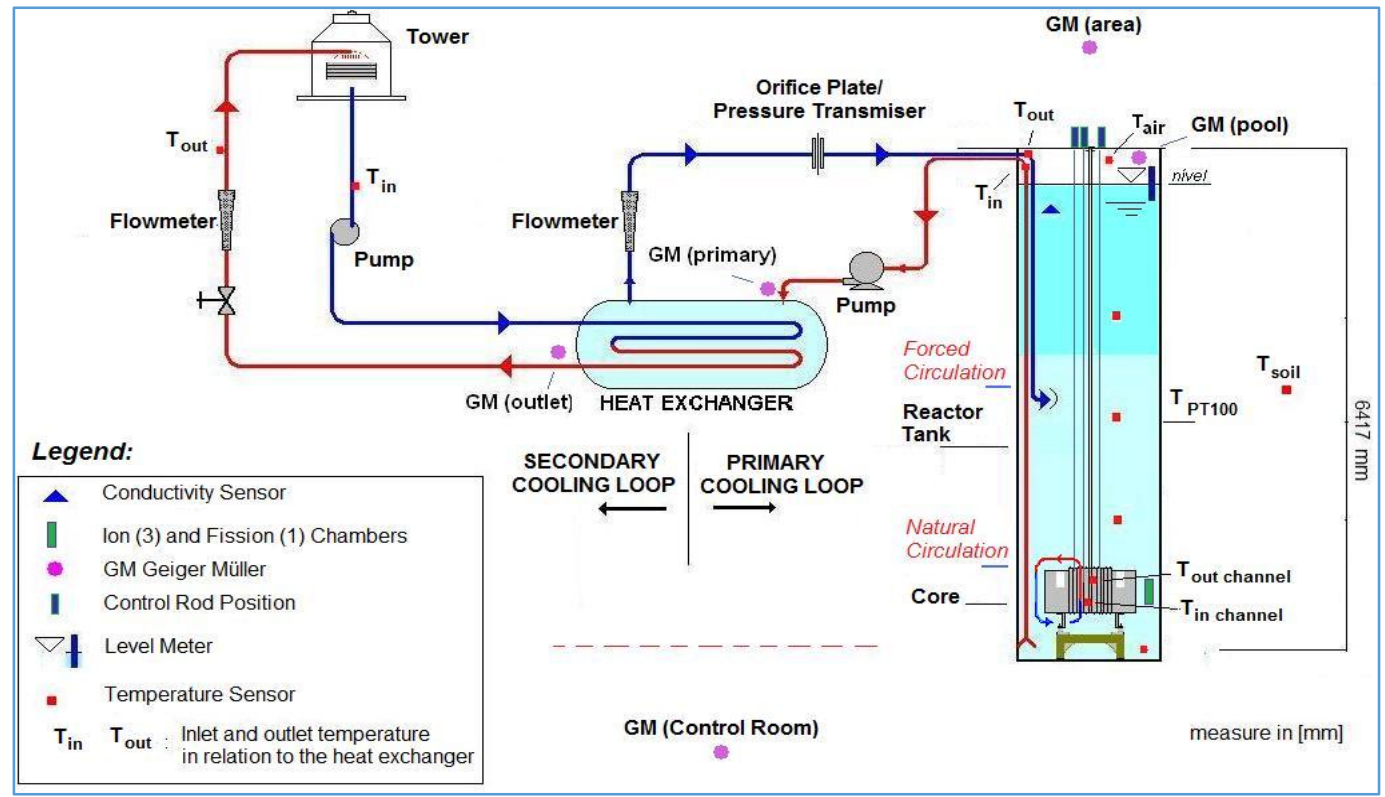

Figure 2 IPR-R1 Triga reactor cooling system and instrumentation distribution

Nuclear reactors are highly complex systems, containing several subsystems operating under the supervision of a hierarchical structure composed of directors, supervisors and operators trained and trained over a long period. Be nuclear power reactors, be research nuclear reactors, the requirements of operation safety are also severe. Thus, the training of these operators is a key factor for ensuring the safety of these facilities [2].
For nuclear research reactors, the IAEA has developed a safety guides on training and qualification aiming the well training of operators [3]. It includes the nature of the operational organization and guidance on its establishment; the recruitment process for reactor personnel, including the required qualifications; the initial training and recycling programs of personnel and the authorization process for individuals whose functions were an immediate relationship with safety. 
According to the guide, the training methods cover, among other recommendations, training in simulators.

The IAEA [3] reinforces the need to use computational tools that satisfactorily simulate the behavior of the systems and subsystems of a nuclear reactor as a way of training operators under various operating conditions. The focus of that document is to present up-to-date information on classification, selection and use of simulators for education and training.

In 2017, a project began to offer a didactic and support tool for professionals who take courses in reactor operators, taught at CDTN $[4,5]$. The project aims to develop, based on the concept of Virtual Instruments (VI's) [6]. The system described here allows training for students and nuclear reactor operators. It allows allowing to visualize the behavior of a nuclear research reactor through a user-friendly interface. It makes it possible to know the relationship between the various operating variables without having to start the reactor.

Thus, a computer simulator was developed for the IPR-R1 Triga reactor using the using the LabVIEW® (Laboratory Virtual Instruments Engineering Workbench) program. LabVIEW® uses the current conception of virtual instruments (VI's) using computer processor and visual interface in video screen. This paper presents the design and results of the user visual interfaces developed for this simulator system.

Figure 3 shows the IPR-R1 Triga reactor console, which will be reproduced in the visual user interfaces presented in this paper.

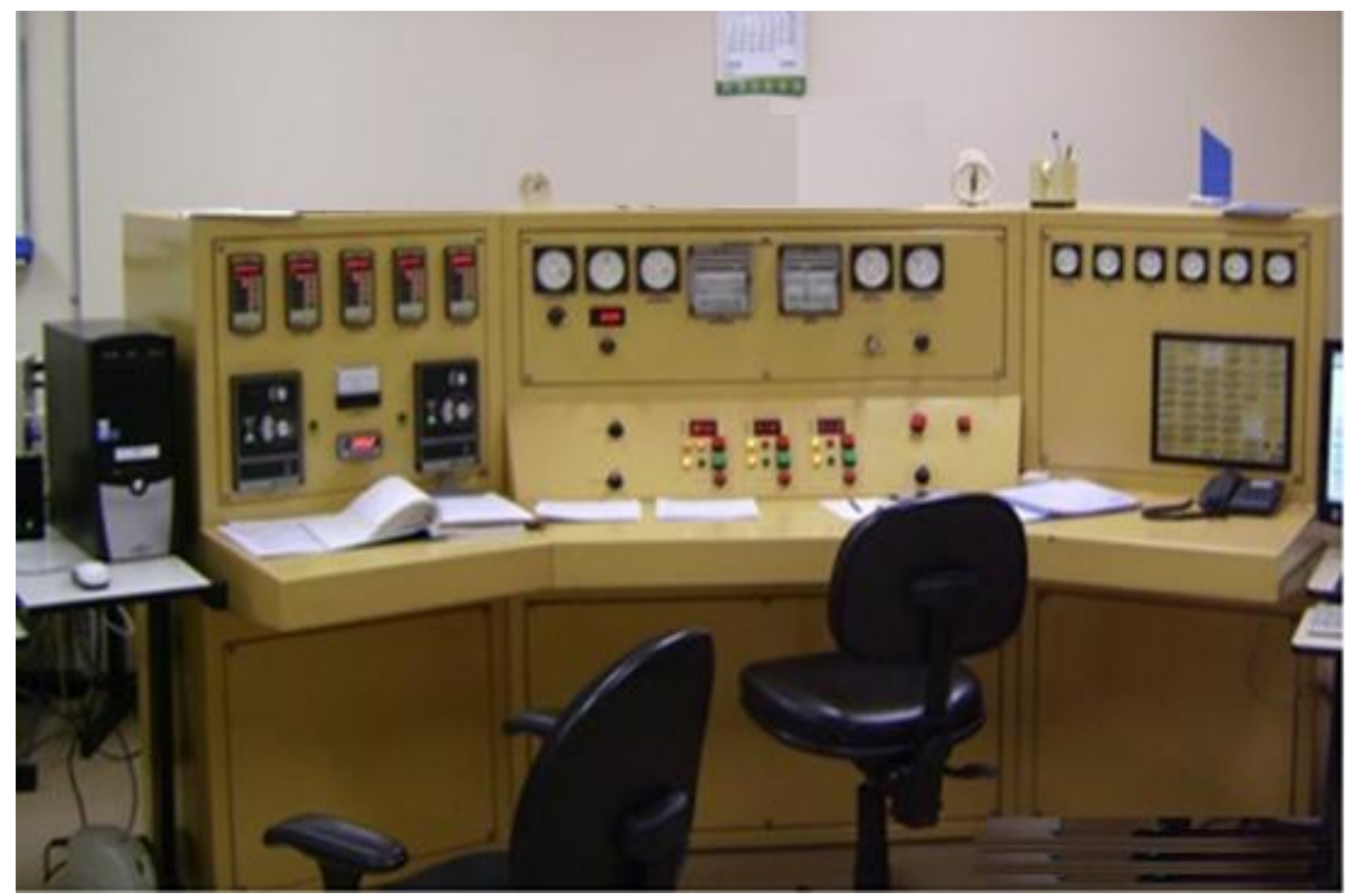

Figure 3 Control panel of the IPR-R1 Triga reactor

\section{Metodology}

Nuclear reactor computer simulators are numerical codes (which may contain multiple codes) to provide an insight and understanding of the plants, as well as a clear understanding of the operational characteristics of the reactors. Simulators are educational tools for training. They seek to provide general response characteristics of selected types of reactors systems.

Having developed the program section responsible for the user interface, it was proceeded to develop the block diagram [4]. This is the equivalent part of structured text programming. Therefore, the most important part of the simulator. To show how each 
step was developed, it is described below according to the console parts of the IPR-R1 Triga reactor.

In addition to the three panels that divided the control console in this work, the curve that relates the period to reactivity (inhour curve) was also drawn up in the simulator. This chart does not exist on the console but has been added to the simulator due to its didactic importance.

2.1Left panel: coolant temperature and right panel: radiation and alarms

To determine the values that would configure situations of "attention" or "alarm", the material of the Training Course for Research Reactor Operator (Ctorp) was used [7]. To model the equations that govern each of the temperatures presented on the panel, a large database was used, the result of years of sampling of reactor operations [7, 8]. Thus, it was possible to build the logic for triggering alarms and relate the increase in temperature with the increase in the reactor power.

In addition to temperature control, the left panel contains controllers and indicators for conductivity, level and water flow. The conductivity control was designed by consulting the limit values as reported in Ctorp[7]. However, instead of raising the conductivity equation based on data collection, a random number generator was used to eventually trigger its respective alarm. For the level and flow indicators, random number generators were also used. The reason for using these generators is due to the low values obtained in the data collection for these indicators.

On the right panel are the radiation level indicators, in different regions of the control room and the refrigeration circuit, the alarm panel and four push buttons reset. The equations that govern the behavior of radiation were raised using the same database used for the analysis of temperatures [8, 9]. Its values, ie: attention limit and limit exceeded, were obtained from Ctorp data, as well as for the values of temperatures and conductivity [7]. The other alarms and their respective effects on the operation of the reactor were also raised as informed in the Operation Handbook of the IPR-R1 Triga Reactor [10]. To test the alarm conditions that do not depend on the operational factors evaluated in this work, a supervisor panel was built.

This panel has pushbuttons that directly trigger alarms that are not triggered during normal reactor operation. But, that were inserted in the simulator, to be used in the trainings to verify their proper actions in reactor operation.

\subsection{Central Panel: Power and Control Channels}

The central panel is the main part of the simulator, and relates to all other parts of the panel. In this part there are: the control rod position controllers (neutron absorbers); power graphics and indicators; period; reactivity; neutron count rate; key for different operation modes; emergency button, reset; rearm; drop rod; reactor power dial's. Thus, it was necessary for the parts of the panel to relate. For example, based on the power values, there are different temperatures and radiation levels for different sectors of the reactor or the control room. In order for the control rods to act on the simulator, just like on the control console, the data collected from the operations database was used [8]. From these data, an adjustment was made so that the values found in the simulator would agree with the values obtained in the normal operations of the reactor.

The increase in power $(P)$ or neutron flux of a nuclear reactor is performed by the following equation [7]:

$P(t)=P_{0} e^{t / T}$

Were:

$P=$ transient reactor power $(\mathrm{W})$,

$P_{0}=$ initial reactor power $(\mathrm{W})$,

$T=$ time during the reactor transient (s),

$T=$ reactor period $(\mathrm{s})$.

The period $(T)$ is the time for the reactor power (or neutron flux) to change by a factor " $\mathrm{e}$ " (Euler number, about 2.718).

The nuclear chain reaction can be described in terms of the multiplication factor $(k)$. It is defined as the ratio of the number of fissions in a generation, divided by the number of fissions in the previous generation.

The term that has been adopted as quite practical in the reactor analysis, to describe its behavior when $k$ deviates from 1 is called reactivity and is the most important parameter in the operation of the nuclear reactor. Reactivity $(\rho)$ is the measure of the distance from the criticality position, as a function of the multiplication factor. 
In nuclear research reactors, it is customary to express reactivity as the inverse of the hour or "inhour". Being the reactivity that will lead to a stable period of 1 hour, that is $3600 \mathrm{~s}$. Thus, it find an equation that relates reactivity $(\rho)$ and stable period $(T)$, with $k \approx 1[11]$ :

$\rho=\frac{\ell_{p}}{T(1+\delta k)}+\sum_{i=1}^{6} \frac{\beta_{i}}{1+\lambda_{i} T}$

Where;

$\rho=$ reactivity

$T=$ reactor period $(\mathrm{s})$;

$\ell_{\mathrm{p}}=$ prompt neutron generation average lifetime (s), about $100 \mu \mathrm{s}$;

$\delta k=$ excess multiplication constant;

$\beta_{i}=$ delayed neutron fraction for group $i$;

$\lambda_{i}=$ decay constant of delayed neutron group $i\left(\mathrm{~s}^{-1}\right)$.

Prompt neutron lifetime $\ell_{\mathrm{p}}$ is the average time elapsing between the neutron release in a fission reaction and its loss from the system by absorption or escape.
The best way is to calculate numerically and present the results in a table or graph. Figure 4 shows the calculation results, presented in graph form, for the IPR-R1 Triga research reactor [7].

The control of a nuclear reactor is feasible due to the existence of some neutrons that appear in the fission process long after the prompt neutrons. These neutrons are called delayed neutrons and are due to the decay of some uranium fission products. There are about 20 delayed neutron precursors. However, for practical purposes, only six groups are considered. The Greek letter $\beta$ is used to represent the total fraction of these neutrons. Each group ( $i)$ is characterized by the half-life $t_{i}$ (or by the disintegration constant $\lambda$ ) of the precursor and by the proportion $\lambda_{\mathrm{i}}$. of the group's neutrons in relation to the number of fission neutrons. Table 1 shows some information on thermal neutrons in uranium-235 fission [11].

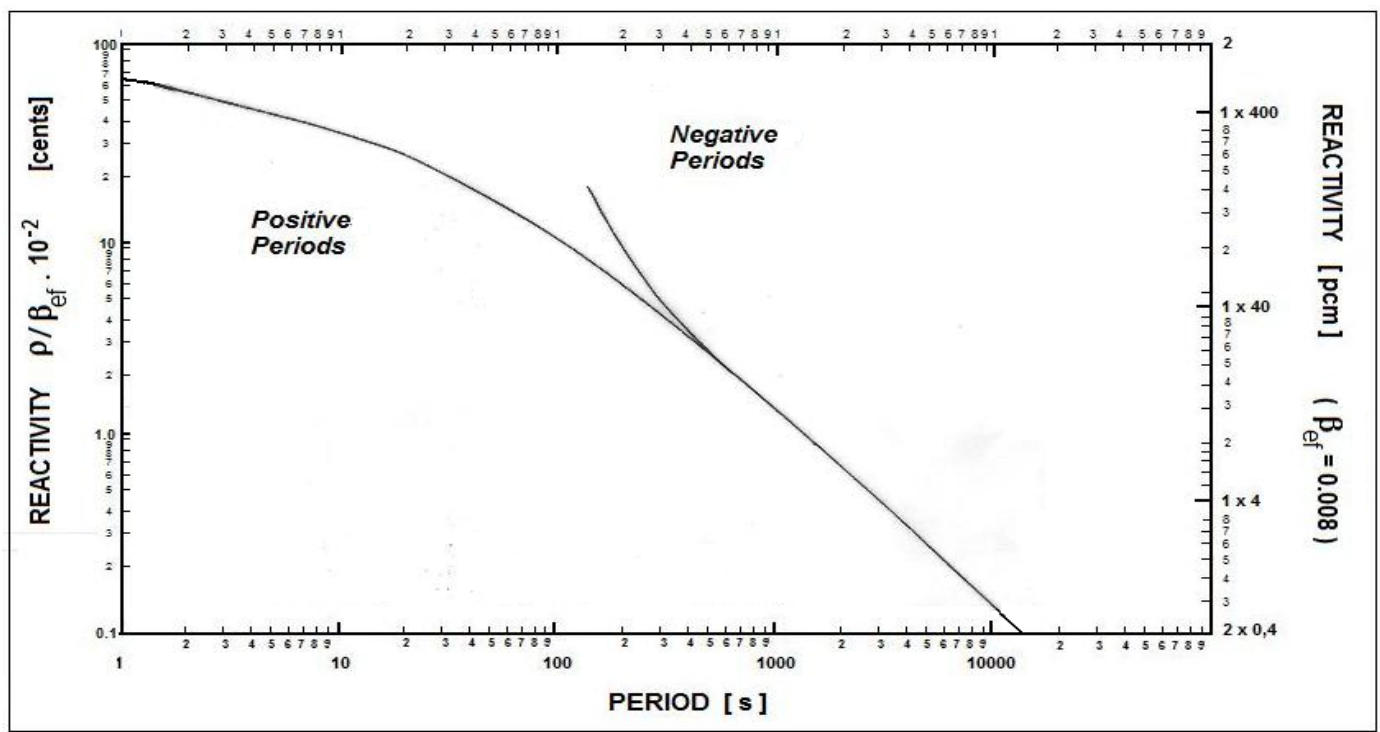

Figure 4 Relationship between reactor period and reactivity (inhour equation) [7].

Table 1 Delayed neutrons fractions from thermal fission of ${ }^{235} \mathrm{U}$ at IPR-R1 Triga reactor [11].

\begin{tabular}{|c|c|c|}
\hline Group $i$ & Delayed neutrons fraction $\beta_{i}$ & Decay constant $\lambda_{i}(\mathrm{~s})$ \\
\hline 1 & 0.022 & 0.013 \\
\hline 2 & 0.145 & 0.032 \\
\hline 3 & 0.131 & 0.12 \\
\hline 4 & 0.242 & 0.31 \\
\hline 5 & 0.083 & 1.39 \\
\hline 6 & 0.027 & 3.85 \\
\hline
\end{tabular}




\section{Results}

Figure 5 presents part of the block diagram code responsible by inhour curve. Figure 6 shows how the inhour curve is presented to the user on the computer screen.

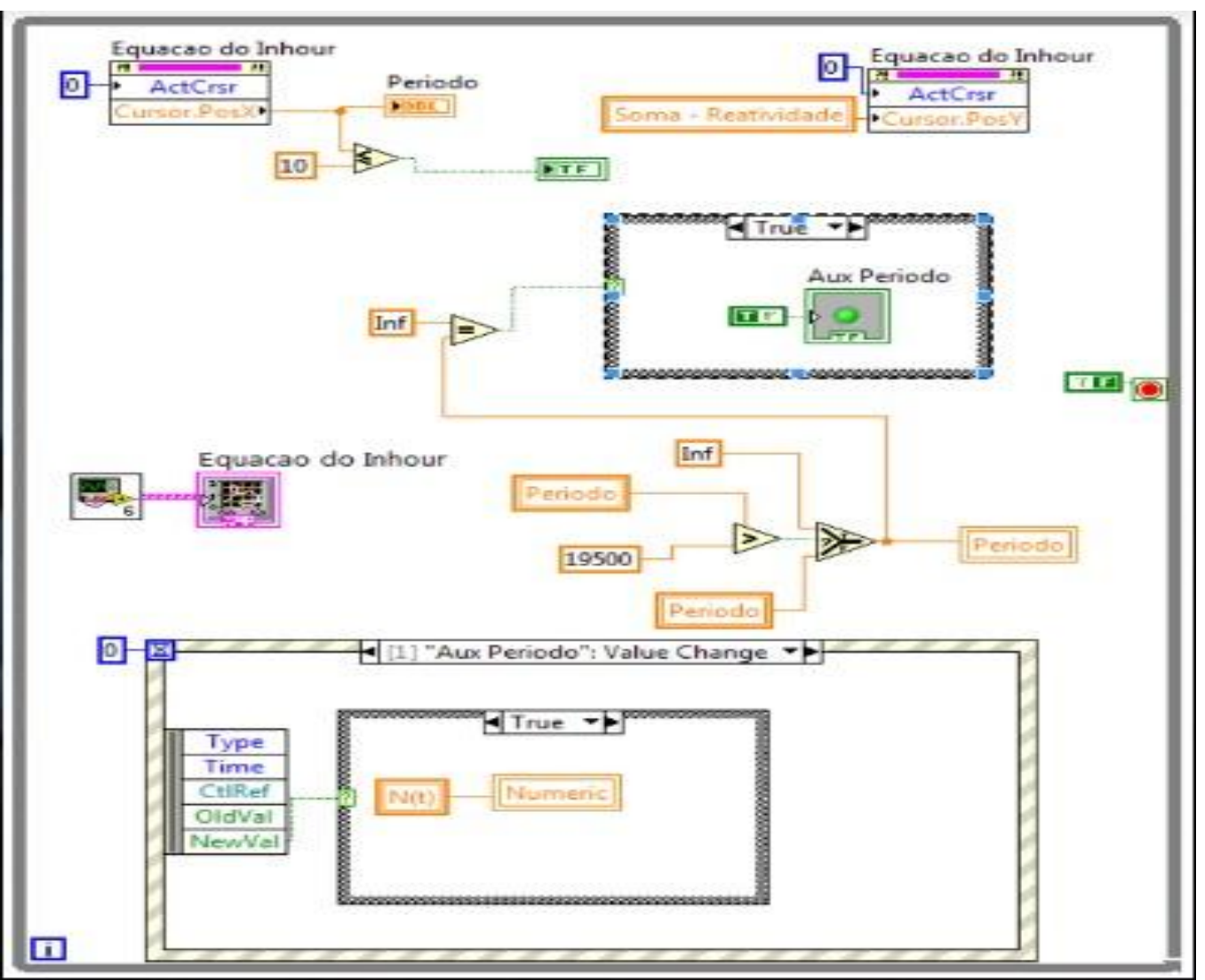

Figure 5 Block diagram code of the inhour curve

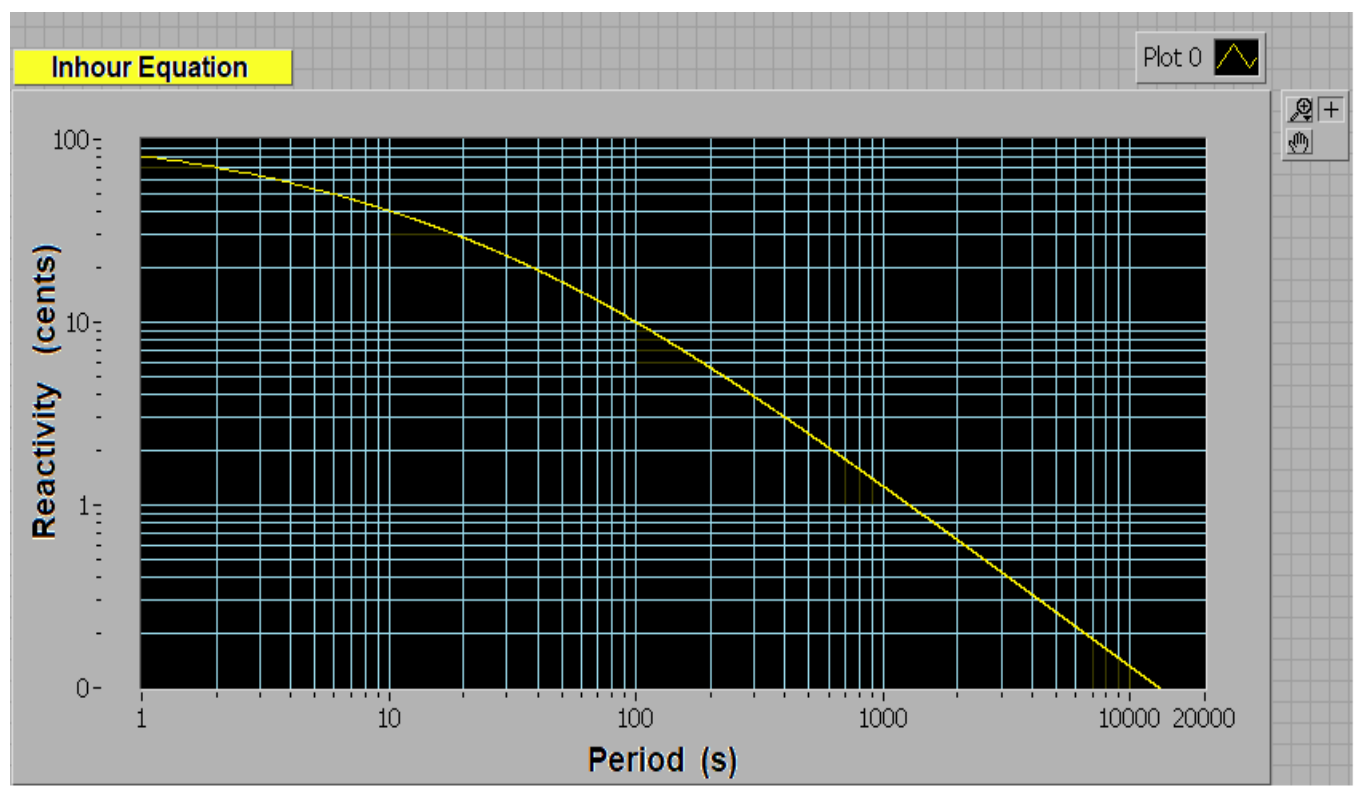

Figure 6 User interface developed for the inhour curve 
3.1Left panel: coolant temperature and right panel: radiation and alarms

With the developed simulator system, it was possible to compare the results obtained during the simulation with the data collected in the normal operations of the reactor. Thus, one can validate the equations (block diagram) inserted in the program. To work in reactor criticality condition, a previously determined position configuration was used.

Figure 7 presents part of the code diagram responsible for the console Left Panel: coolant temperature control, and Right Panel: radiation monitoring and alarms. Diagrams similar to this one have been developed for all sections of the control console.

Through the LabVIEW® platform, it was possible to build the front panel in order to resemble the console of the reactor's control room $[4,5]$. Thus, it allows an operator to act on the simulator in a friendly way. The user interface seeks to approximate, as much as possible, the reality found by the operator as shown in Figure 8 and Figure 9.

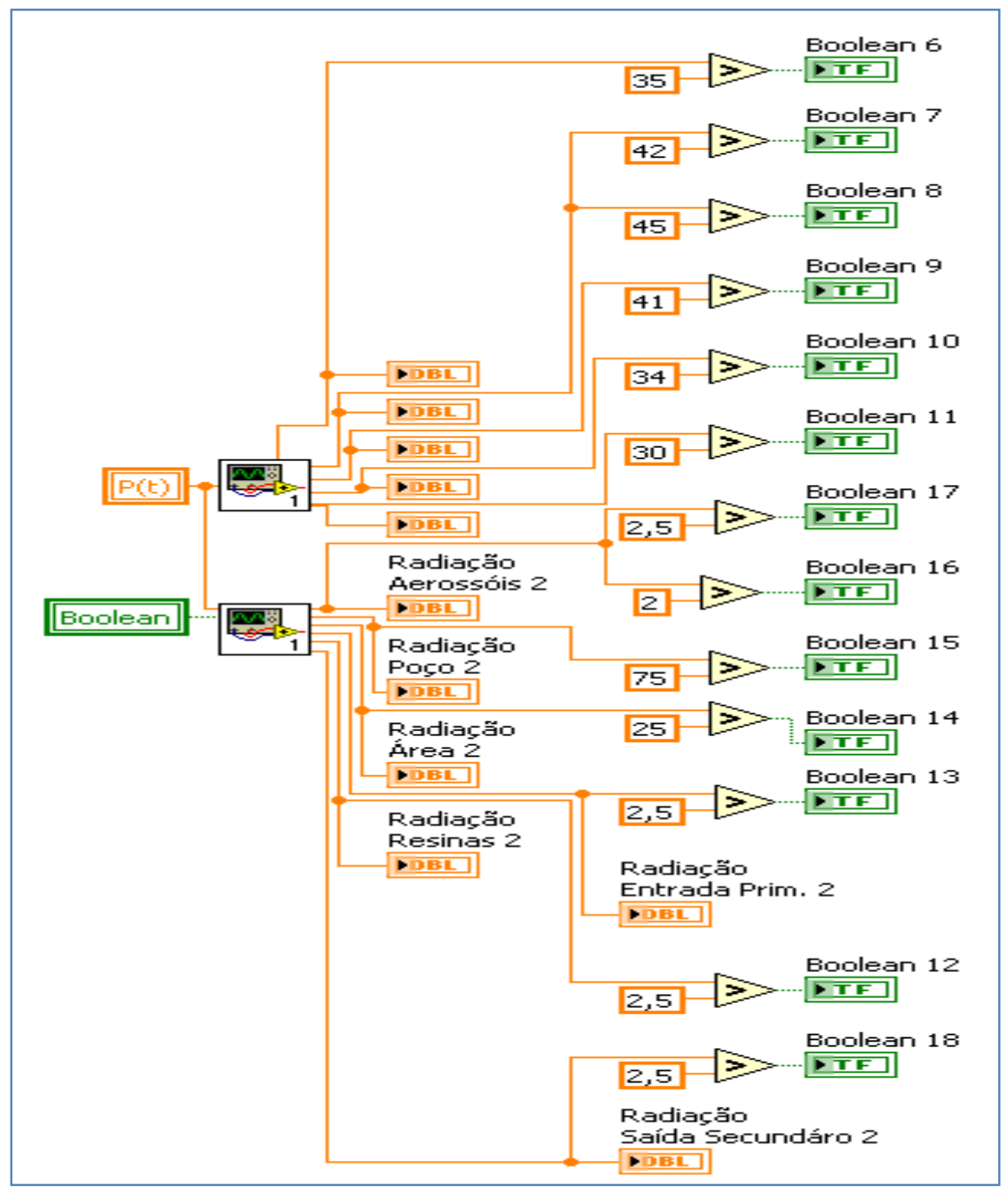

Figure 7 Code responsible for monitoring temperatures and radiation 
ACCENTS Transactions on Image Processing and Computer Vision, Vol 6(21)

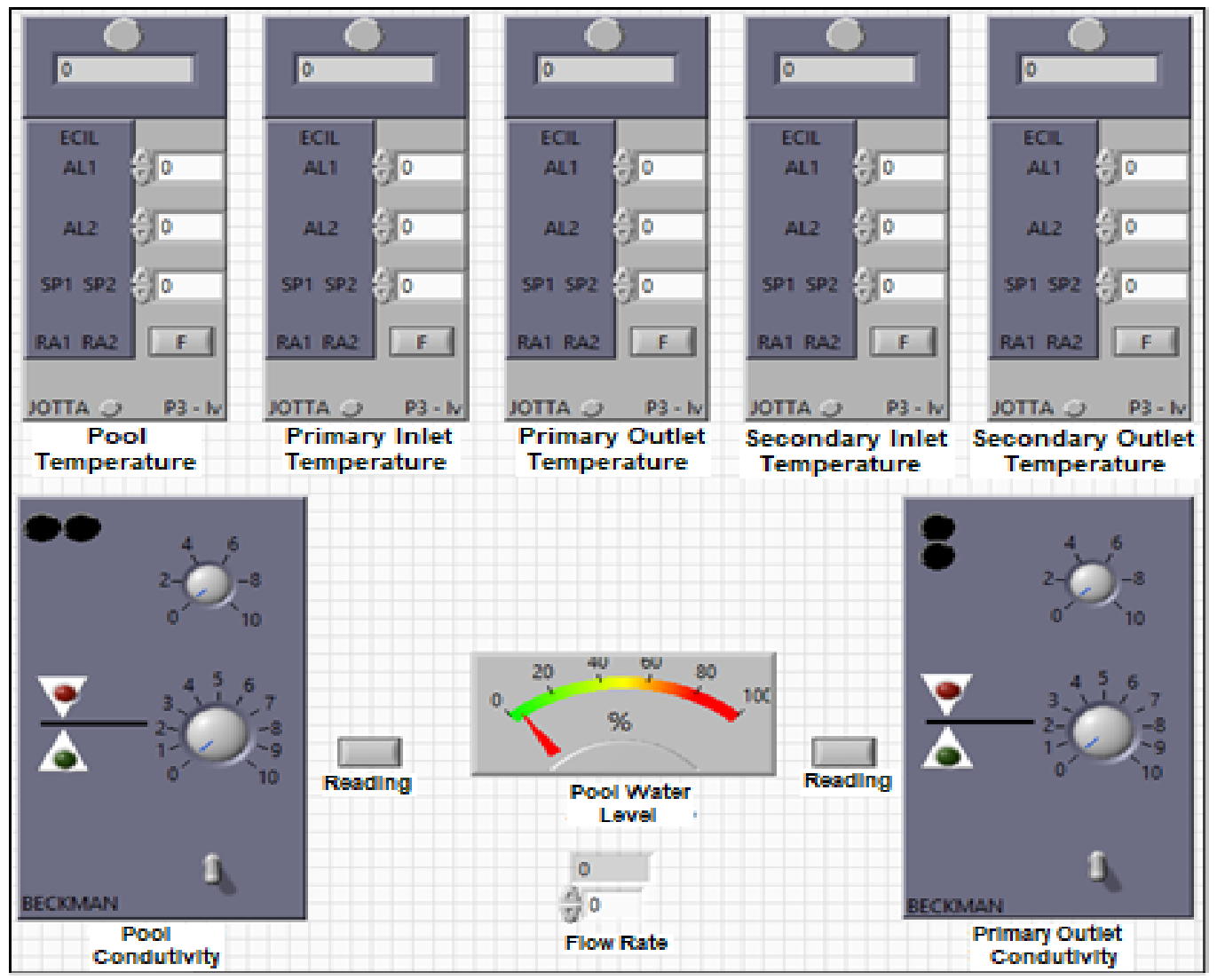

Figure 8 Visual interface for the left part of the console: coolant temperatures

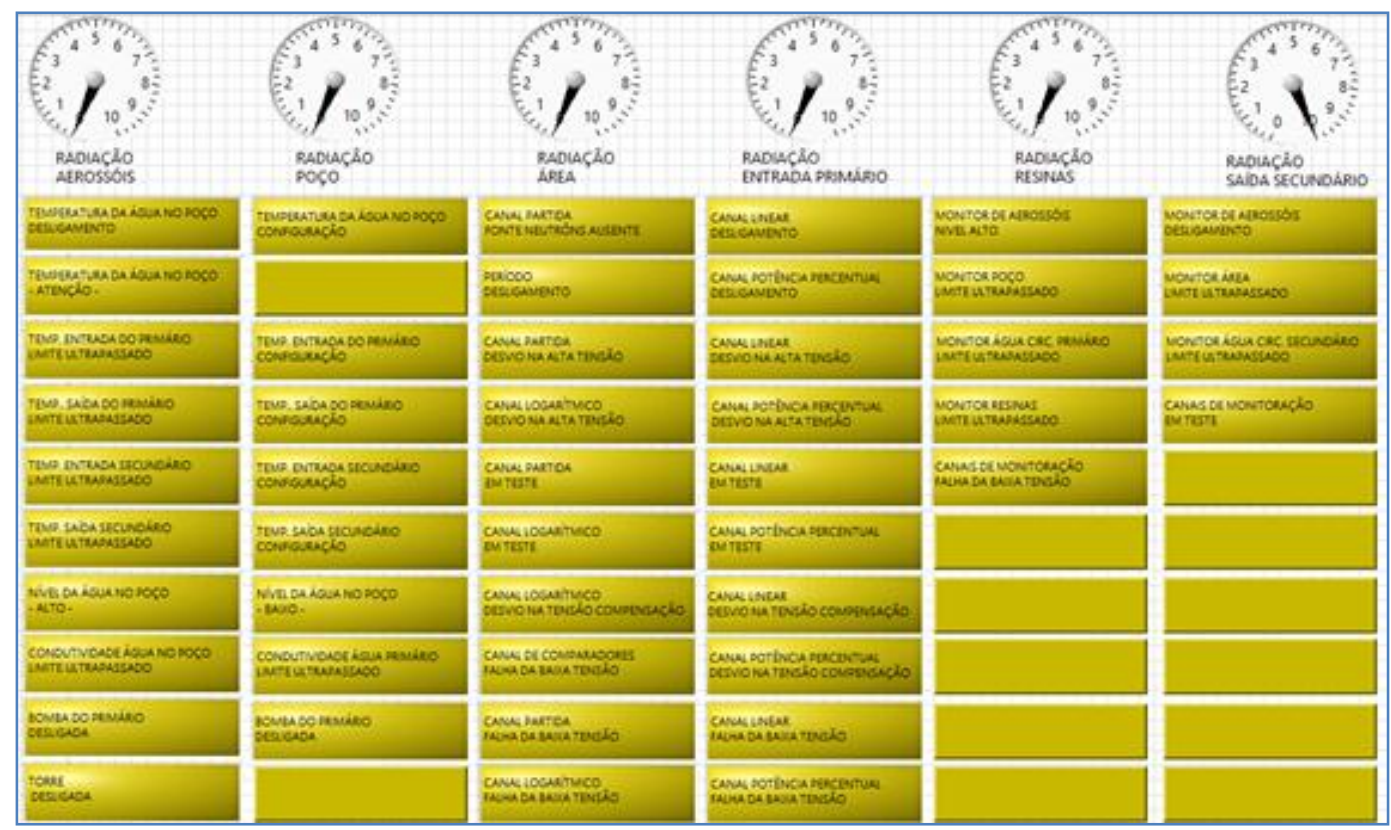

Figure 9 Visual interface for the right part of the control table: radiation monitoring and alarm panel 
3.2Central panel: power and control channels

The central part of the reactor control console is the part responsible for the operation of the reactor. The act in its control implies the alteration of all the other operational parameters. As an example, the diagram configuration that acts on the positions of the control rods is shown in Figure 10. Figure 11 shows the visual interface of the central board of the control console. The user when controlling the position of the control bars implies changes in the neutron flow and, consequently, in the reactor power.
The alarms and interlocks routine operate similarly to the operation of the control console. The block diagram responsible for controlling the entire simulator system was developed in order to meet the routine of pre-operational and operational procedures, based on the documentation of the IPRR1 Triga reactor [10]. Thus, to start the reactor, the operator must turn on the General Switch, then activate the "Power" switch and, finally, activate the "Reset" button, allowing the user to activate the boom position controllers.

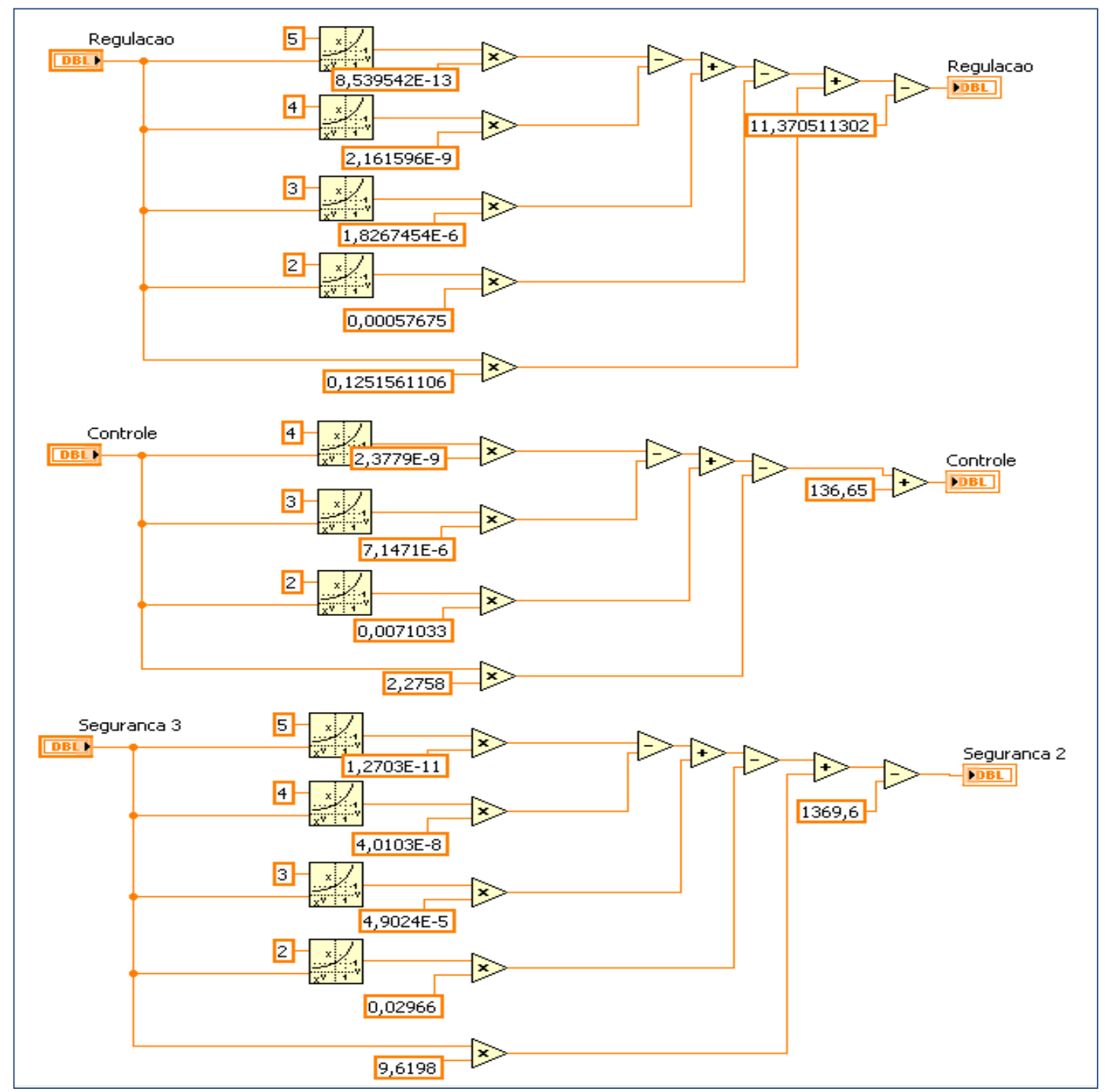

Figure 10 Block diagram for the control rods positions 


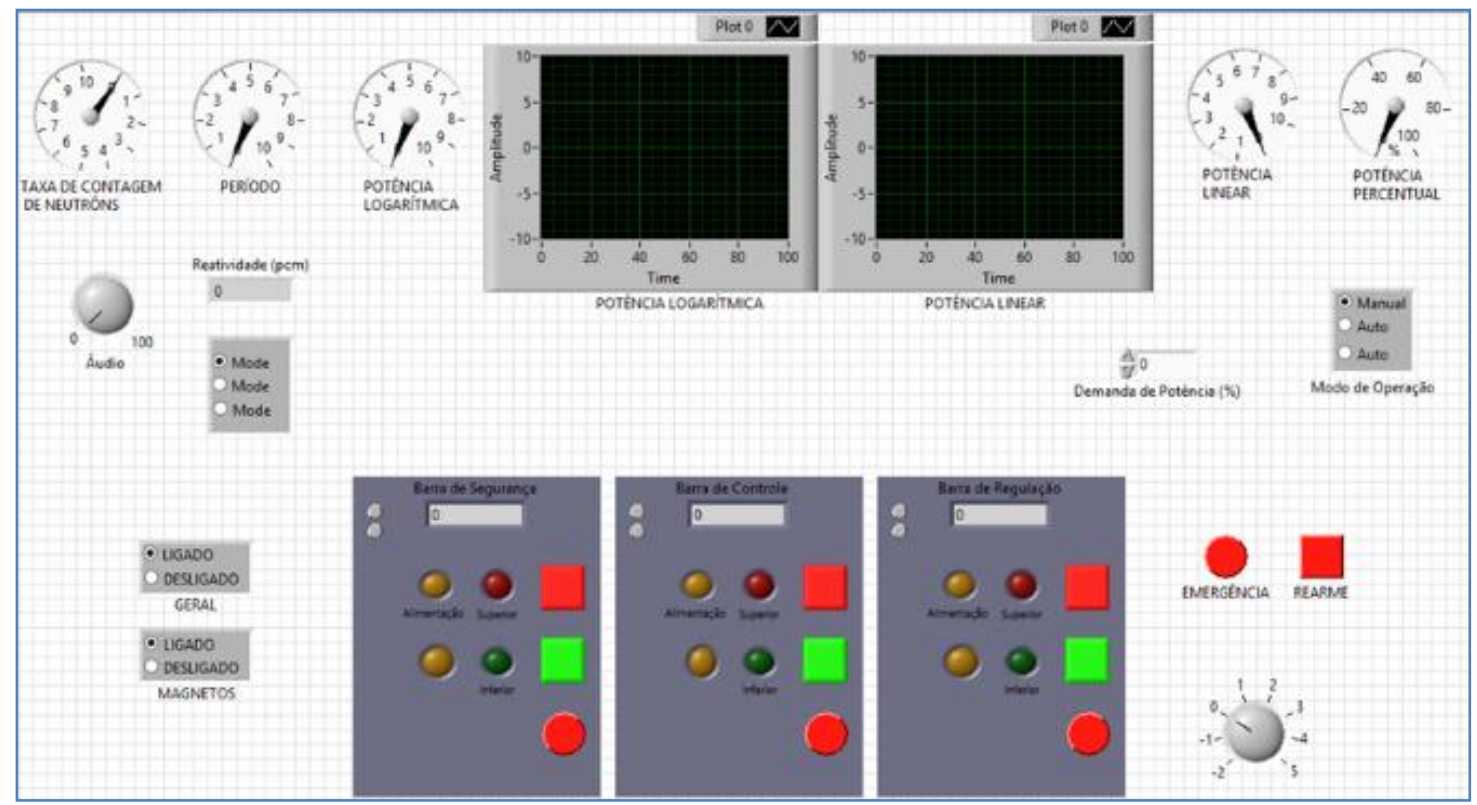

Figure 11 Interface for the central part of the reactor console: power control and control rod positions

\section{Conclusion}

The IPR-R1 Triga nuclear research reactor located at the Nuclear Technology Development Center $(\mathrm{CDTN})$ is an institution managed by the Brazilian Nuclear Energy Commission (Cnen). The IPR-R1 Triga nuclear research reactor located at the Nuclear Technology Development Center (CDTN) is an institution managed by the Brazilian Nuclear Energy Commission (Cnen). The IPR-R1 is used for education, particularly for the needs of the Brazilian Nuclear Power Plants personnel training. Thus, it was developed a digital system that simulates the behavior of the main variables related to the routine startup of the reactor in order to assist in the training conducted in this reactor. Nuclear engineering and physics students can carry out experimental exercises on this computational simulator system [12]. It performs simulation of the main reactor operational variables, also allows easy navigation between HMI (Human-Machine Interaction) screens providing a globalized supervision of neutronic, and thermohydraulic processes. It was possible to show the feasibility of integrating a supervisory system and a software to perform mathematical calculations with the data obtained from real experiments. The benefits and advantages of using the simulator based on personal computers during the training programs of operators and undergraduate and graduate students were shown. Improvements to human-machine interfaces can be implemented to make the simulator more effective in training.
Nuclear control organizations have encouraged its member countries to use nuclear reactor simulators to be used in training and teaching courses [13]. Thus, this work meets the recommendations of the IAEA. Visual interfaces can be increasingly improved to meet the objectives of the courses to be taught.

\section{Acknowledgment}

This work is supported by the following institution: Nuclear Technology Development Centre (CDTN), Brazilian Nuclear Energy Commission (Cnen), Research Support Foundation of the State of Minas Gerais (Fapemig), and Brazilian Council for Scientific and Technological Development (CNPq).

\section{Conflicts of interest}

The authors have no conflicts of interest to declare.

\section{References}

[1] Mesquita AZ, Rezende HC. Experimental investigation temperature patterns in the IPR-R1 triga nuclear reactor. In 3rd World Triga Users Conference, Belo Horizonte, Minas Gerais, Brazil, 2020.

[2] Da Silva Rocha M, de Andrade DA, Casorla M. Computer simulator for the research reactor IPEN/MB-01. Brazilian Journal of Radiation Sciences. 2020.

[3] International Atomic Energy Agency. The operating organization, and the recruitment, training and qualification of personnel for research reactors. IAEA Safety Standards Series No. NS-G-4.5. 2008.

[4] M F L Aldo, Z M Amir, Felippe A A M. Digital system project for graphic simulation of operational parameters of the IPR-R1 Triga nuclear research 
reactor. ACCENTS Transactions on Image Processing and Computer Vision. 2018; 4(12):26-32.

[5] Lage AM, Felippe AA, Mesquita AZ. Design of a digital system for operational parameters simulation of IPR-R1 Triga nuclear research reactor. Brazilian Journal of Radiation Sciences. 2019.

[6] https://www.ni.com/en-in.html. Accessed 12 August 2019.

[7] Laboratório Da. Centro de desenvolvimento da tecnologia nuclear (CDTN). Comunicação via e-mail. 2017.

[8] Mesquita AZ, Souza RM. The operational parameter electronic database of the IPR-R1 TRIGA research reactor. In proceedings of the 4th world TRIGA users conference 2008.

[9] Mesquita AZ, Rezende HC, Santos AA, Palma DA. Performance of some operating parameters of a TRIGA research reactor in natural convective cooling. International Journal of Nuclear Energy Science and Technology. 2014; 8(1):61-71.

[10] CDTN/Cnen. Operation Manual of the IPR-R1 Triga Reactor. Belo Horizonte, MO/TRIGA-IPR-R1/CDTN, 2001.

[11] https://ansn.iaea.org/Common/documents/Training/TR IGA\%20Reactors\%20(Safety\%20and\%20Technology )/intro/start_tmtrr.htm. Accessed 12 September 2019.

[12] Mesquita AZ, Souza RM, Ferreira AV, Dalle HM, Costa AC. The utilization of IPR-R1 TRIGA nuclear research reactor for educational purposes in Brazil. 2011.

[13] IAEA - International Atomic Energy Agency. PCTRAN Generic Pressurized Water Reactor Simulator Exercise Handbook. https://www.iaea.org/. Accessed 12 September 2019.

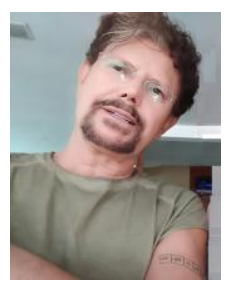

Amir Zacarias Mesquita is a Doctor of Science in Chemical Engineering, Unicamp, Brazil (2005), Master of Science and Nuclear Technologies UFMG/Brazil (1981); Graduated in Electrical Engineering - UFMG/Brazil (1978). He is a Researcher, Nuclear Reactor Senior Operator, and PostGraduate Professor. He is involved in research in Nuclear Engineering with an emphasis on Reactor Technology, thermo-fluid dynamics and reactor physics.

Email: amir@cdtn.br

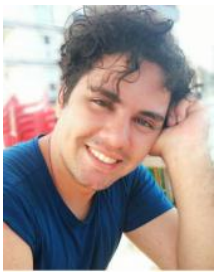

Adriano De Almeida Massaud Felippe is a graduate in Control and Automation Engineering from the Federal University of Minas Gerais UFMG (Brazil), January 2016. He is a technician graduated in Industrial Automation from the Technical College of UFMG/Coltec (Brazil) in 2015. He holds a scholarship in Scientific Initiation from the Nuclear Technology Development Center (CDTN).

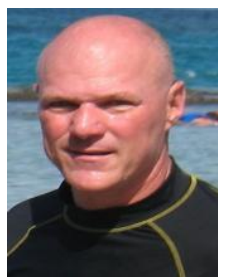

Aldo Márcio Fonseca Lage graduated with a bachelor's degree in mathematics from Fafi-BH, Brazil (1993). He completed the Specialization Course in Systems Analysis at Fafi-BH (Brazil) (1995). He holds an MS in Technology of Radiation, Minerals and Materials from CDTN/Cnen, Brazil (2005), as well as the Technical Electronic Course from ColtecUFMG/Brazil (1983). He has experience in the area of Computer Science, with emphasis on Computer Systems. He primarily focuses on the following subjects: Simulation, Modelling, Nuclear Reactors, Instrumentation, the Triga Reactor, and Neutronic Parameters.

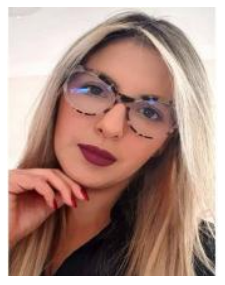

Patrícia Albernaz Melo Ribeiro is a graduantion in Civil Engineering from the Pontifical Catholic University of Minas Gerais - PUC, Brazil, (2014). She has a degree in physics (degree). He has a postgraduate degree in paving and road restoration, a postgraduate degree in sanitary engineering and the environment, a postgraduate degree in astronomy teaching. Master's student at the Nuclear Technology Development Center (CDTN). 